\section{Buchrezension zu: Quorum Sensing}

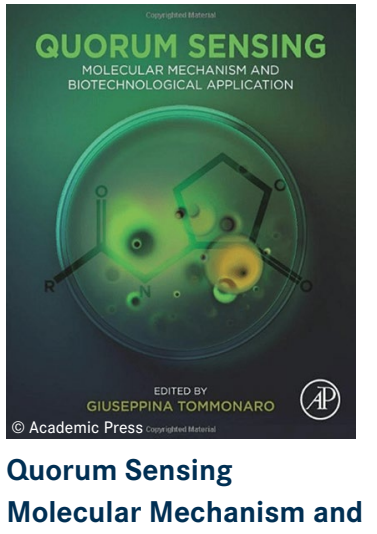

Biotechnological Application

Giuseppina Tommonaro

(Hrsg.)

293 S., Academic Press, 2019. SC, 99,14€.

ISBN: 9780128149058

Auch als E-Book erhältlich

DOI: $10.1007 / \mathrm{s} 12268-020-1328-\mathrm{Z}$

(C) Springer-Verlag GmbH 2020

Quorum sensing (QS) ist eine Form der bakteriellen Zell-ZellKommunikation, die durch die Produktion und Wahrnehmung von Signalmolekülen vermittelt wird und zur Regulation von bestimmten Genen in Abhängigkeit von der Zelldichte führt. OS befähigt Bakterien zu kooperativem Verhalten und spielt eine große Rolle beispielsweise bei der Ausprägung von Virulenz und Biofilmen. Dieses Buch erhebt den Anspruch, nicht nur die molekularen Mechanismen des Quorum sensing darzustellen, sondern darüber hinaus Bezüge zu biotechnologischen Anwendungen herzustellen. Neben der Darstellung von QS in bekannten Modellorganismen, wie beispielsweise Pseudomonas aeruginosa und Vibrio fischeri, widmen sich einzelne Kapitel den extremophilen Prokaryoten, aber auch den komplexen Konsortien des Mikrobioms, der Phyllo- und Rhizosphäre sowie marinen Biofilmen. Ein weiterer großer Teil des Buches stellt die Mechanismen der Inhibition von QS dar. Die Autoren diskutieren speziell und umfassend die Quorum quenching-Enzyme, die Polyphenole und zyklischen Peptide.

Die aufgezeigte Breite von QSMolekülen, OS-Inhibitoren und deren Wirkungsweise im Kontext mit Modellorganismen und Konsortien ist eine Stärke des Buches. Andererseits handelt es sich um eine Zusammenstellung von Übersichtsartikeln, die stets aufs Neue einen Abriss über $\mathrm{OS}$ geben, sodass (zu) viele Abschnitte redundant sind. Das Buch enthält eine überschaubare Anzahl an Schwarz-Weiß-Abbildungen. Eine größere Zahl von Abbildungen und Schemata würde dem Leser helfen, mehr Freude beim Lesen und Eindringen in neue Forschungsgebiete zu haben. Der Titel verheißt ein tolles Werk, seinem hohen Anspruch wird das Buch aber nur bedingt gerecht.

Kirsten Jung,

Ludwig-Maximilians-Universität

München

jung@lmu.de 